\title{
Correction to: Long noncoding RNA IncARSR promotes nonalcoholic fatty liver disease and hepatocellular carcinoma by promoting YAP1 and activating the IRS2/AKT pathway
}

Yuan Chi, Zheng Gong, He Xin, Ziwen Wang and Zhaoyu Liu*

\section{Correction to: J Transl Med (2020) 18:126}

https://doi.org/10.1186/s12967-020-02225-y

Following publication of the original article [1], the authors identified an error in Fig. 4. The flow cytometry was used to detect the cycle changes of different groups of cells. The authors found that the results were biased due to the improper selection of parameters in flow cytometry. The flow cytometry results were carefully re-analyzed and corrected in Fig. 4g. The incorrect and correct figure are included in this Correction article. The original article has been updated. 


\section{Correct Figure 4:}

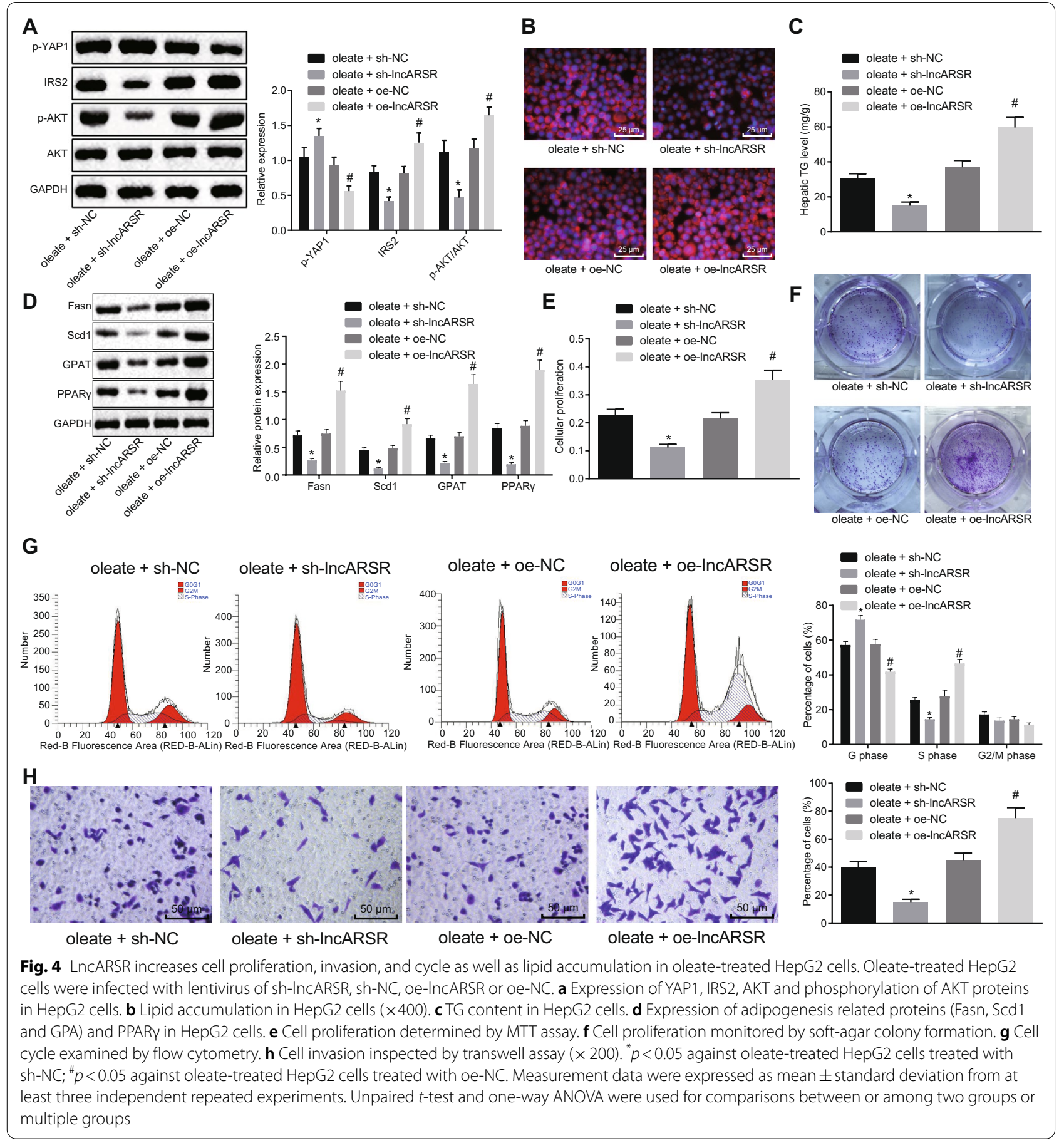




\section{Incorrect Figure 4:}

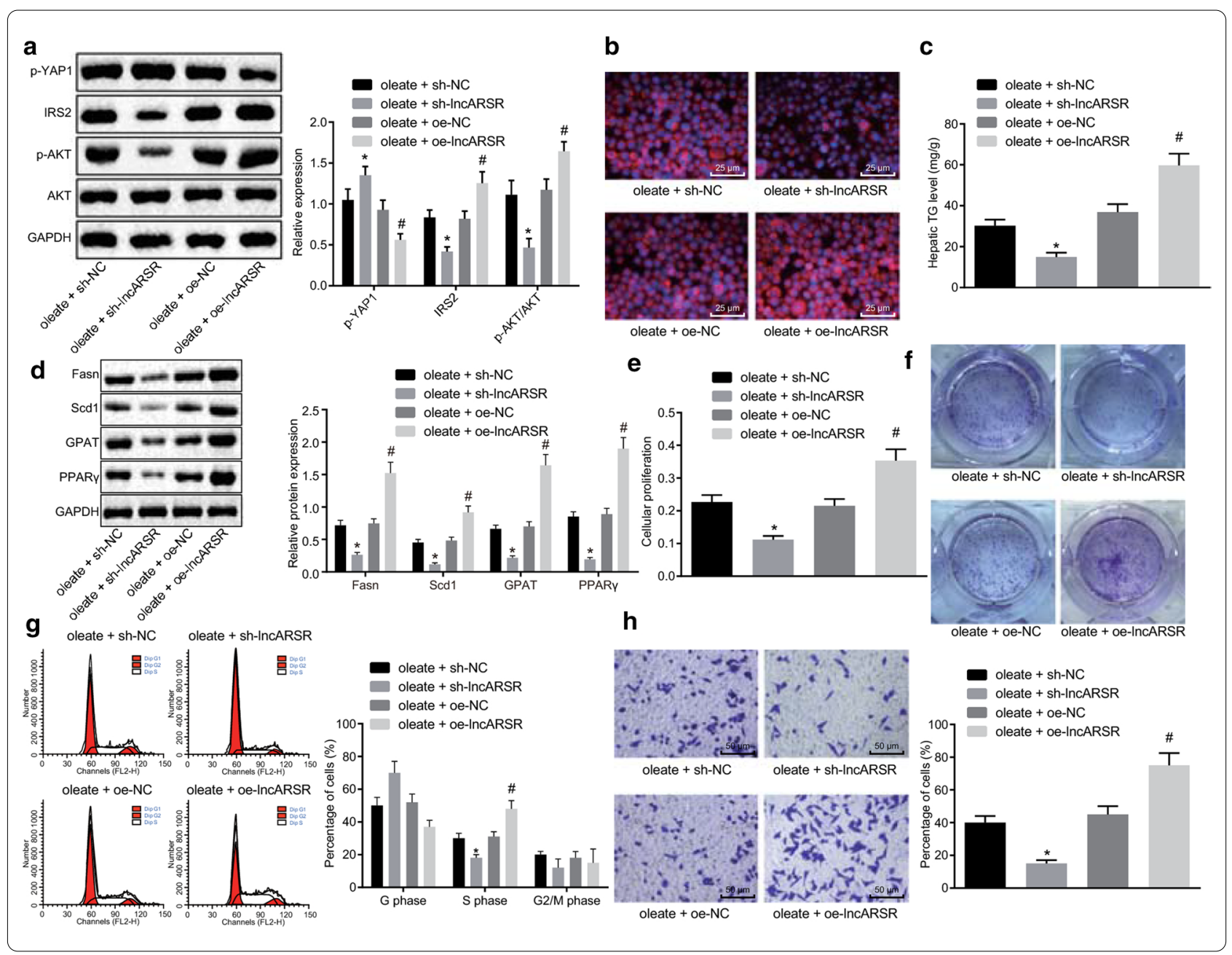

Published online: 19 October 2021

\section{Reference}

1. Chi Y, Gong Z, Xin H, Wang Z, Liu Z. Long noncoding RNA IncARSR

promotes nonalcoholic fatty liver disease and hepatocellular carcinoma by promoting YAP1 and activating the IRS2/AKT pathway. J Transl Med. 2020;18:126. https://doi.org/10.1186/s12967-020-02225-y.

\section{Publisher's Note}

Springer Nature remains neutral with regard to jurisdictional claims in published maps and institutional affiliations. 